\title{
Patrimônio Arquitetônico Na Paisagem Cultural Da Avenida São João
}

Architectural Heritage In The Cultural Landscape Of Avenida São João

Patrimonio Arquitectónico En El Paisaje Cultural De La Avenida São João

\author{
Rosio Fernández Baca Salcedo \\ Professora Doutora, UNESP, Brasil. \\ rosiofbs@faac.unesp.br \\ Victor Rüegger Lucredi \\ Mestrando, UNESP, Brasil. \\ victor.lucredi@gmai.com
}




\section{RESUMO}

Os centros históricos representam o traçado inicial da cidade, logo, a preservação da sua paisagem cultural, mais especificamente seu patrimônio arquitetônico é relevante para a história, a memória e a identidade. A paisagem cultural da Avenida São João, do centro histórico de São Paulo, passou por constantes transformações e descaracterizações. Nos anos de 1968 e 1988, as edificações relevantes para a história, arquitetura e cultura, foram tombadas pelo Conselho de Defesa do Patrimônio Histórico, Arqueológico, Artístico e Turístico do Estado de São Paulo (CONDEPHAAT) e pelo Conselho Municipal de Preservação do Patrimônio Histórico, Cultural e Ambiental da Cidade de São Paulo (CONPRESP), respectivamente. Neste contexto, o presente trabalho visa examinar se as ações dos tombamentos realizados pelo CONDEPHAAT e CONPRESP levaram a preservar a paisagem cultural da Avenida São João. A análise da paisagem cultural da Avenida São João foi realizada em função de dois cronotopos: da gênese e o momento atual; e segundo categorias fundamentadas por Rapoport: elementos fixos, semifixos e não fixos. Os resultados indicam que a paisagem cultural da Avenida São João se manteve até 1910, após esta data a paisagem sofreu transformações até os tombamentos realizados pelo CONDEPHAAT e COMPRESP que levaram a preservar o patrimônio Arquitetônico em sua paisagem cultural.

PALAVRAS-CHAVE: Paisagem Cultural. Tombamento. Centro Histórico.

\section{ABSTRACT}

The historical centers represent the initial layout of the city, thus preserving its cultural landscape, more specifically its architectural heritage is relevant to history, memory and identity. The cultural landscape of Avenida São João, in the historical center of São Paulo, has undergone constant transformations and alterations. In 1968 and 1988, buildings relevant to history, architecture and culture were named by the Council for the Defense of Historic, Archaeological, Artistic and Tourist Heritage of the State of São Paulo (CONDEPHAAT) and by the Municipal Council for the Preservation of Historic Patrimony, Cultural and Environmental Affairs of the City of São Paulo (CONPRESP), respectively. In this context, the present work aims to examine if the actions of the taps made by CONDEPHAAT and CONPRESP led to preserve the cultural landscape of Avenida São João. The analysis of the cultural landscape of Avenida São João was carried out in function of two chronotopes: of the genesis and the moment current; and according to categories based on Rapoport: fixed, semi-fixed and non-fixed elements. The results indicate that the cultural landscape of Avenida São João was maintained until 1910, after that date the landscape underwent transformations until the falls made by CONDEPHAAT and COMPRESP that led to preserve the Architectural heritage in its cultural landscape.

KEY WORDS: Cultural Landscape. Safeguard. Historic center.

\section{RESUMEN}

Los centros históricos representan el trazado inicial de la ciudad, luego, la preservación de su paisaje cultural, más específicamente su patrimonio arquitectónico es relevante para la historia, la memoria y la identidad. El paisaje cultural de la Avenida São João, del centro histórico de São Paulo, pasó por constantes transformaciones y descaracterizaciones. En los años 1968 y 1988, las edificaciones relevantes para la historia, arquitectura y cultura, fueron tomadas por el Consejo de Defensa del Patrimonio Histórico, Arqueológico, Artístico y Turístico del Estado de São Paulo (CONDEPHAAT) y por el Consejo Municipal de Preservación del Patrimonio Histórico, Cultural y Ambiental de la Ciudad de São Paulo (CONPRESP), respectivamente. En este contexto, el presente trabajo busca examinar si las acciones de la salvaguarda realizados por el CONDEPHAAT y CONPRESP llevaron a preservar el paisaje cultural de la Avenida São João. El análisis del paisaje cultural de la Avenida São João fue realizado en función de dos cronotopos: de la génesis y el momento actual; y según categorías basadas en Rapoport: elementos fijos, semifijos y no fijos. Los resultados indican que el paisaje cultural de la Avenida São João se mantuvo hasta 1910, después de esta fecha el paisaje sufrió transformaciones hasta las salvaguardas realizadas por el CONDEPHAAT y COMPRESP que llevaron a preservar el patrimonio arquitectónico en su paisaje cultural.

PALABRAS CLAVE: Paisaje Cultural. Salvaguardar. Centro histórico. 


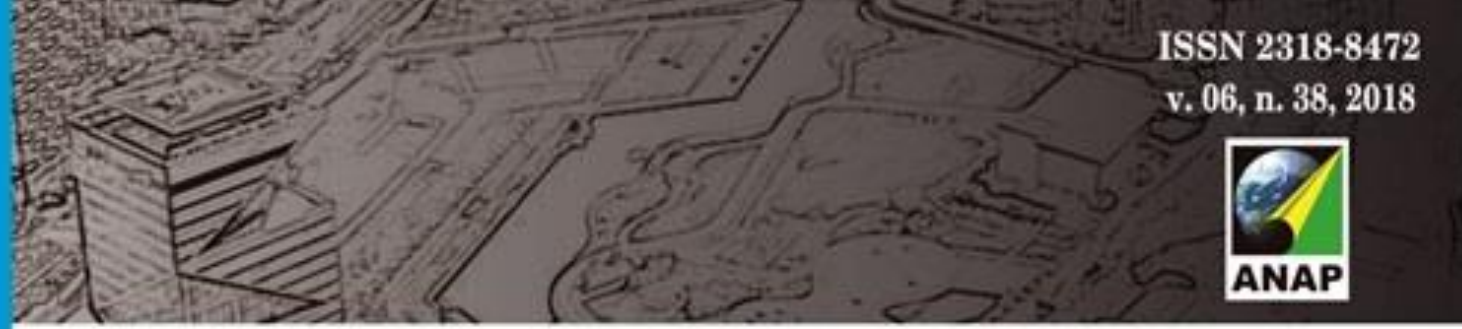

Gerenciamento de Cidades

\section{INTRODUÇÃO}

Os centros históricos representam principalmente o "traçado inicial da cidade, são estruturas urbanas e arquitetônicas que expressam as manifestações políticas, econômicas, sociais, culturais e tecnológicas, das formações sociais dos diferentes períodos históricos" (SALCEDO, 2007, p. 15). Estas áreas concentram comércio, serviços, finanças e habitações para uma diversidade de grupos sociais. A preservação da paisagem cultural no centro histórico é relevante para a história, a memória e a identidade. Entenda-se que:

(...) quanto mais modificado está a paisagem pelos homens, tanto mais cultural é. As paisagens mais modificadas - povoados são culturais por excelência. Incluso os caçadores e recoletores já modificavam consideravelmente a paisagem no processo de caça ou recoleta, ao acender o fogo, etc. (RAPOPORT, 2003, p. 53).

Ruskin (2008) ressalta que: "podemos viver sem a arquitetura de uma época, mas não podemos recordá-la sem a sua presença.", ou seja, "a memória seja ela coletiva ou individual, é sempre seletiva, só nos lembramos daquilo que queremos lembrar. Por essa razão, a memória é parcial, descontinua e vulnerável a todas as utilizações e manipulações" (ABREU, 1998, p. 87).

Abreu (1998, p. 87) conclui que "a memória da cidade, que referencia obrigatoriamente essas mesmas lembranças a uma base material precisa de um determinado lugar". Segundo Vargas e Castilho (2006),

\footnotetext{
Recuperar o centro das metrópoles nos dias atuais significa (...) melhorar a imagem da cidade que (...) cria um espírito de comunidade e pertencimento. Significa também promover a reutilização de seus edifícios e a consequente valorização do patrimônio construído; otimizar o uso da infraestrutura estabelecida; dinamizar o comércio como qual tem relação de origem; gerar novos empregos. Em suma, implementar ações em busca da atração de investimentos, de moradores, de usuários e de turistas que dinamizem a economia urbana e contribuam para a melhoria da qualidade de vida, valorizando também a gestão urbana que executa a intervenção (VARGAS; CASTILHO, 2006, p. 5).
}

Um dos mecanismos para a preservação da paisagem cultural é o tombamento, Ato administrativo realizado pelo Poder Público, nos níveis federal, estadual ou municipal.

Em São Paulo, o centro histórico, teve uma significativa parcela de sua área tombada por resoluções do CONDEPHAAT e do CONPRESP, que só colaborou para que a paisagem cultural da mesma fosse mantida em grande parte intacta, como é o caso da Avenida São João. Neste contexto, o trabalho visou examinar se as ações de tombamento na Avenida São João realizados tanto pelo CONDEPHAAT em 1968 e pelo CONPRESP em 1988 levaram a preservar o patrimônio Arquitetônico em sua Paisagem Cultural. 


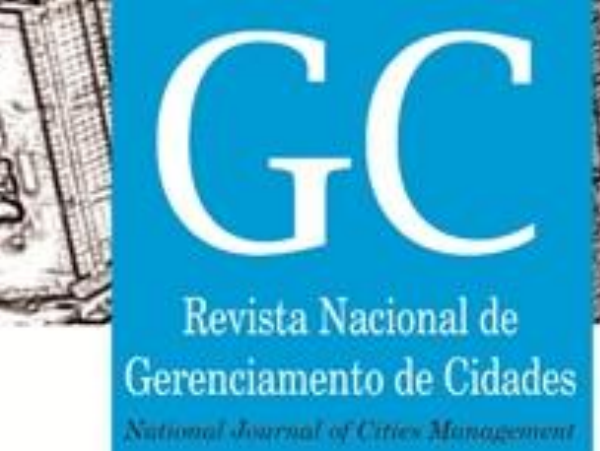

\section{OBJETIVO}

O presente trabalho visa examinar se as ações dos tombamentos realizados pelo CONDEPHAATE CONPRESP levaram a preservar a paisagem cultural da Avenida São João.

\section{MÉTODO}

O método utilizado é o urbanismo dialógico com base na fundamentação teórica de Muntañola, Bakthin, e Rapoport; no caso, analisa-se o texto (paisagem cultural da Avenida) na relação com o contexto (centro histórico), em dois momentos cronotópicos: sua gênese e os dias atuais.

Na primeira etapa, no contexto do Centro Histórico de São Paulo, formado pelos: Distrito da República e Distrito da Sé; serão estudados os aspectos históricos, urbanos, sociais, econômicos e culturais. A pesquisa sobre a região do Centro Histórico será realizada a partir da revisão da bibliografia: livros, teses, dissertações e artigos.

Na segunda etapa, o texto ou configuração da paisagem cultural da Avenida São João será analisada com base em dois cronotopos - 1: a gênese; 2: o momento atual. Também serão identificados os edifícios tombados pelos órgãos CONDEPHAAT e CONPRESP. Sobre a paisagem cultural, a analise terá como base os elementos fundamentados por Rapoport (2005): elementos fixos, semifixos e não fixos:

- Fixos: edifícios, ruas, quadras, praças, parques, infraestrutura (rede de energia elétrica, água, esgoto).

- Semifixos: mobiliário, vegetação, comunicação visual.

- Não fixos: pessoas, trânsito, carros.

\section{CENTRO HISTÓRICO DE SÃO PAULO: AVENIDA SÃO JOÃO}

A Avenida São João está localizada no centro histórico de São Paulo, estendendo-se por uma distância de aproximadamente 1.930 metros do ponto que vai no epicentro da cidade de São Paulo, próximo ao Edifício Altino Arantes (Banespão) até emendar-se com o Elevado Presidente João Goulart (Minhocão) (Figura 1). 


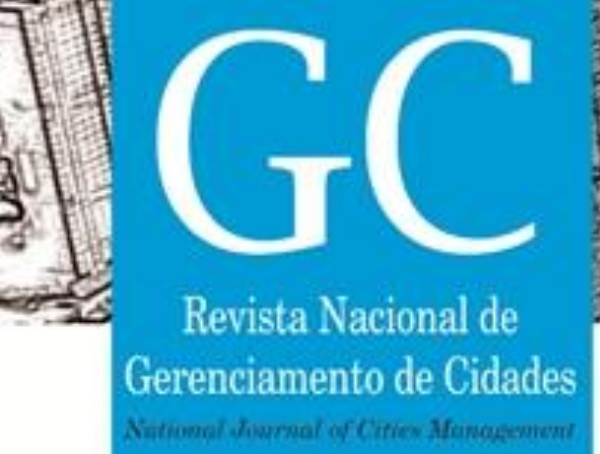

ISSN $2318-8472$

Figura 1 - Centro histórico de São Paulo: Distritos da Sé e República
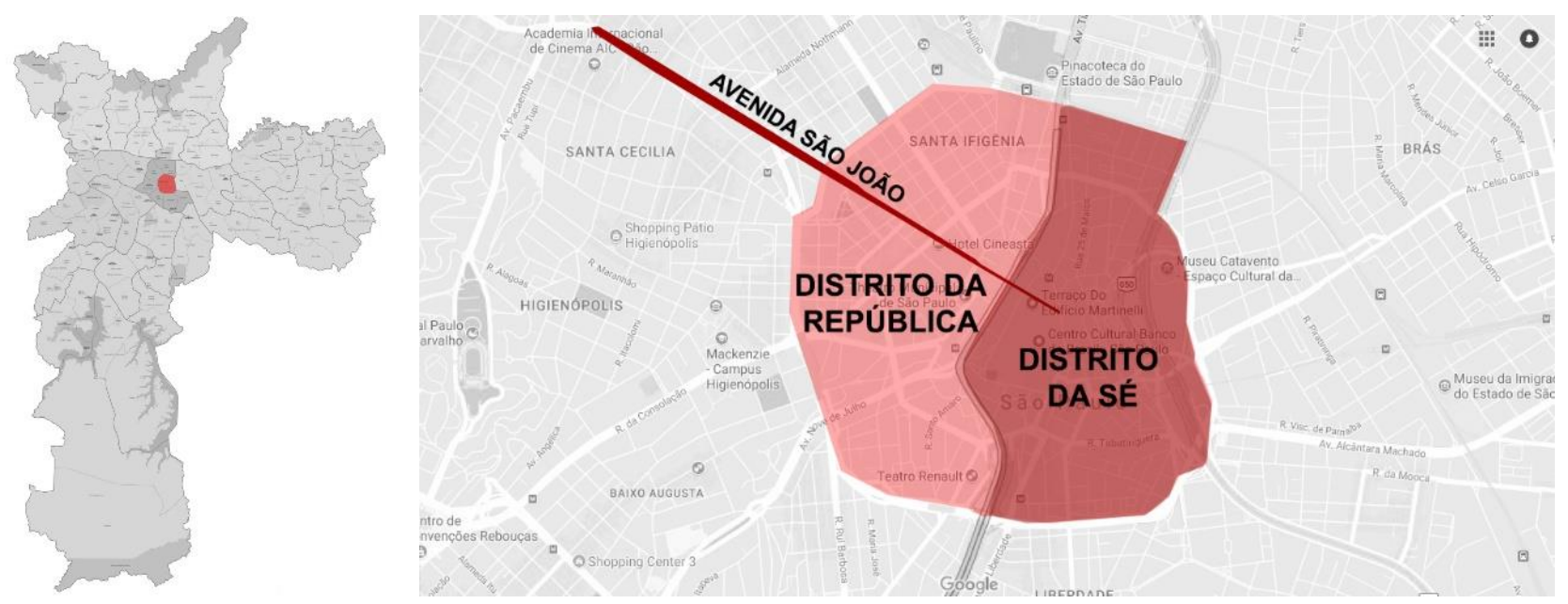

Fonte: SÃO PAULO, editado pelo autor.

Fundada em 1554 pelos padres Jesuítas, São Paulo surgiu em 25 de janeiro de daquele ano a partir da construção de um colégio Jesuíta realizada na colina histórica de Piratininga. Em 1560 teve o início do povoamento da região hoje conhecida como "Páteo do Colégio", por se tratar de uma zona em local mais alto e mais plana, podendo servir também como proteção aos ataques indígenas. Em 1711, a Vila de São Paulo, já capital da capitania, foi elevada para posição de cidade (SÃO PAULO, 2017).

Nesse momento, a cidade desenvolve-se ao redor dessa região, hoje localizada no Distrito da Sé.

Com o crescimento da cidade, onde hoje é existente o Distrito da República, a cidade vai sendo ampliada. Entende-se por centro histórico de São Paulo, as regiões pertencentes aos Distritos da Sé e da República.

Nota-se em convergência a esse centro histórico foi o deslocamento da população da região central para regiões periféricas ao longo das décadas (CARLI, 2012): comércio, serviços e finanças que saíram do centro histórico para a criação de outras centralidades, o que tem levado a "um significativo esvaziamento ao mesmo tempo em que as periferias crescem extensivamente, pesando sobre as redes de infraestrutura" (MARICATO, 2001, p. 137). Isso gerou depreciação do centro histórico, tornando muitas áreas do mesmo abandonadas, como é possível analisar pela Tabela 1. 
Tabela 1: População no centro de São Paulo, anos 1991, 2000 e 2010.

\begin{tabular}{lccc}
\hline Distritos & $\mathbf{1 9 9 1}$ & $\mathbf{2 0 0 0}$ & $\mathbf{2 0 1 0}$ \\
\hline Bela Vista & $\mathbf{7 1 . 8 2 5}$ & 63.190 & 64.359 \\
Belém & 49.697 & 39.622 & 41.180 \\
Bom Retiro & 36.136 & 26.598 & 28.822 \\
Brás & 33.356 & 25.158 & 28.009 \\
Cambuci & 37.069 & 28.717 & 29.306 \\
Consolação & 66.590 & 54.522 & 52.806 \\
Liberdade & 76.245 & 61.875 & 64.270 \\
Moóca & 71.999 & 63.280 & 61.855 \\
Pari & 21.299 & 14.824 & 15.634 \\
República & 57.797 & 47.718 & 49.469 \\
Santa Cecília & 85.829 & 71.179 & 72.096 \\
Sé & 27.186 & 20.115 & 22.574 \\
\hline TOTAL & 635.028 & $\mathbf{5 1 6 . 7 9 8}$ & $\mathbf{5 3 0 . 3 8 0}$ \\
\hline
\end{tabular}

Fonte: Prefeitura de São Paulo, 2011, grifos pelo autor

Na década de noventa, o centro histórico de São Paulo vem diminuindo sua população; em 1991 tinha 84.983 habitantes (SÃO PAULO, 2001) e em 2000 diminui para 67.567 (SÃO PAULO, 2016). Um fator importante como consequência do esvaziamento do centro foi da existência de 45.464 domicílios vagos em 2000, que levou a degradação das edificações e insegurança de esta área. Em 2010, o centro histórico teve um leve aumento da população, passando de 67.567 em 2000 para 72.043 em 2010 (SÃO PAULO, 2011).

Sabido isso, o CONDEPHAAT em 1968 tombou algumas edificações relevantes para a história, a arquitetura e a cultura como o Conservatório Dramático Musical, edifício Martinelli, Hotéis Britânia e Central. E o CONPRESP por meio do Decreto n. ‥ 26.818, de 9 de setembro de 1988, dispôs do tombamento de imóveis localizado no Pátio do Colégio e de outras providências. Estendeu através de outros decretos, entre eles, a Resolução n. ‥ 11/91 - Aditamento à Resolução n. ‥ 06/91 que prevê também o tombamento da área envolta do Teatro Municipal e da área do Vale do Anhangabaú (TEO RES. 06/91).

Um dos mais importantes eixos do Centro Histórico e com uma grande parte de sua paisagem cultural tombada é a Avenida São João. 


\section{PATRIMÔNIO ARQUITETÔNICO NA PAISAGEM CULTURAL DA AVENIDA SÃO JOÃO}

O patrimônio Arquitetônico na paisagem cultural da Av. São João é abordado a partir de seus cronotopos.

Bakhtin define o cronotopo como:

Nós daremos o nome de cronotopo (literalmente, "espaço-tempo") para a ligação intrínseca das relações temporais e espaciais que são artisticamente expressas na literatura. Este termo (tempo-espaço) é empregado em matemática, e foi introduzido como parte da Teoria da Relatividade de Einstein. O significado especial que ela tem na teoria da relatividade não é importante para nossos propósitos, estamos tomando-o emprestado para a crítica literária quase como uma metáfora (quase, mas não totalmente). O que conta para nós é o fato de que ele expressa a inseparabilidade do espaço e do tempo (tempo como a quarta dimensão do espaço). Entendemos o cronotopo como categoria formalmente constitutiva da literatura, não vamos lidar com o cronotopo em outras áreas da cultura (BAKHTIN, [1975] 1988, p. 84).

Muntañola (2007 apud MARTINS, 2015), completa ressaltando que por cronotopo se entende como:

Tempo e lugar ou articulação entre espaço e tempo, isto é, a articulação entre um espaçotempo físico com o espaço-tempo social (relação entre pessoas) e espaço-tempo político (com suas leis e seus costumes, rituais, mitos, etc.). Com isso, é relevante prever, através dos projetos arquitetônicos, qual é a articulação cronotópica (considerar o que já passou, ou seja, a história) e as propostas para o futuro (projeto) entre construir e habitar que estamos impondo à vida humana (MUNTAÑOLA, 2007, p. 6-28 apud MARTINS, 2015, p. 40).

A Avenida São João será analisada segundo dois cronotopos: 1) sua gênese, isto é, sua configuração inicial; 2) momento atual da Avenida com as edificações tombadas pela COMPRESP e pelo CONDEPHAAT.

\subsection{Gênese da paisagem da Avenida São João (1651 até 1911 antes do alargamento da avenida e verticalização)}

A história da Avenida São João se confunde com a história de São Paulo, separadas apenas por 97 anos. O início da Avenida São João remonta a 1651 quando "os paulistanos Henrique da Cunha Gago e Cristóvão da Cunha solicitaram à Câmara Municipal a doação de terrenos na área delimitada pelos Ribeirões Anhangabaú e Yacuba. Nascia assim uma (...) ligação dessas propriedades com a chamada colina histórica de São Paulo" (SÃO PAULO, S/D).

Seu segmento inicial, em meados do século XVIII, era conhecido como Ladeira ou Descida do Acu, em continuidade ao antigo Largo do Rosário. No passado seiscentista, o trecho seguinte, após superar o ribeirão Anhangabaú, servia para se atingir o 'caminho que vai para Piratininga' (pequeníssimo povoado que existia na confluência de córrego de mesmo nome como o rio Tietê na região da Barra Funda, à meio caminho para a Freguesia do Ó. Com o tempo, tanto o córrego quanto o povoado desapareceram quase sem deixar vestígios). Essa 
via era íngreme até ultrapassar a Rua Nova de São José (atual Líbero Badaró), atingir a Ponte do Acu e prolongar-se para adiante do Tanque do Zunega (atual Largo do Paissandu) em trecho já denominado Rua de São João Batista, cuja largura variava entre 6 e 10 metros. (PAULICEIA, 2011, p. 19).

O Córrego do Yacuba também era conhecido com Córrego Guaçu; para transpor o Ribeirão Anhangabaú, ponto mais baixo próximo a ladeira histórica de São Paulo, existia uma ponte conhecida como "Ponte do Acú" (OLIVEIRA, 2014). Com o passar do tempo, esse caminho passou a ser conhecido como "Ladeira da ponte do Acú".

São Paulo, fundada por padres, para homenagear São João, considerado o "protetor das aguas" pelo catolicismo, a Ladeira do Acú foi batizada de "Ladeira de São João Batista".

No dia 28/11/1865, (...) a ladeira "da ponte do Acú" (... foi) denominada como "Ladeira de São João". Mais tarde, ela se transformou em Rua. (SÃO PAULO, S/D).

A rua São João desde sua gênese se configura como área cultural, em 1986 foi construída o Conservatório Dramático Musical e em 1906 foi concluída a construção da Igreja Nossa Senhora do Rosário dos Homens Pretos. A rua manteve preservada suas características originais até 1911, depois de esta data começa s ser alargada (Figura 2).

Analisando a paisagem cultural de acordo com Rapoport (2005), com base nos elementos fixos, semifixos e não fixos existentes na gênese da rua São João, atual Avenida São João, podemos afirmar que:

- Fixos: os edifícios formados como elementos construtivos, alinhadas a calçada com gabaritos de altura até a largura da via, fachadas voltadas diretamente para a rua, janelas baixas, sem grades, portas diretamente para a calçada, etc.; a rua com pavimentação de paralelepípedo com trilhos para a passagem dos bondes, rede elétrica aérea (Figura 3b).

- Semifixos: a Avenida desde sua gênese sempre contou com pouca arborização, postes de iluminação, letreiros comerciais alinhados as fachadas (Figura 2a).

- Não fixos: as pessoas circulavam a pé ou pegavam os bondes para se deslocar. Na rua circulavam alguns automóveis e os bondes para o transporte coletivo (Figura 2c). 


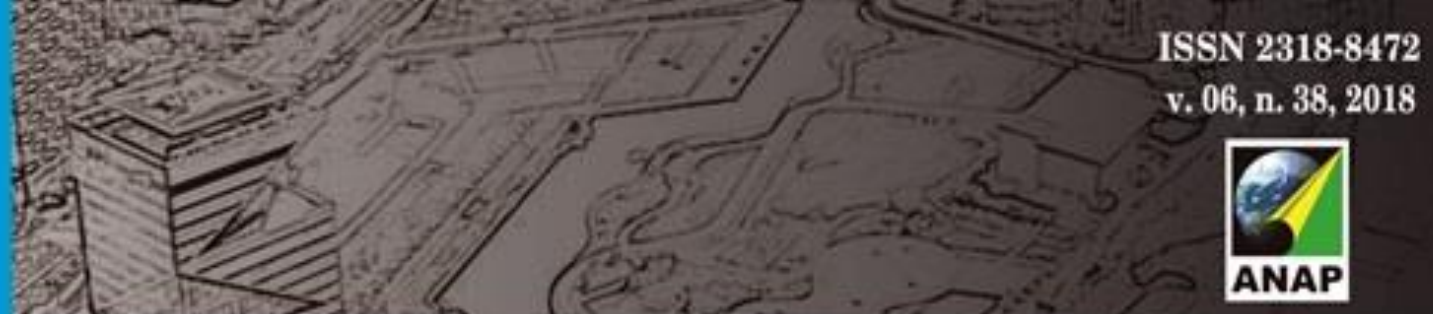

Revista Nacional de

Figura 2 - Rua São João, 1910

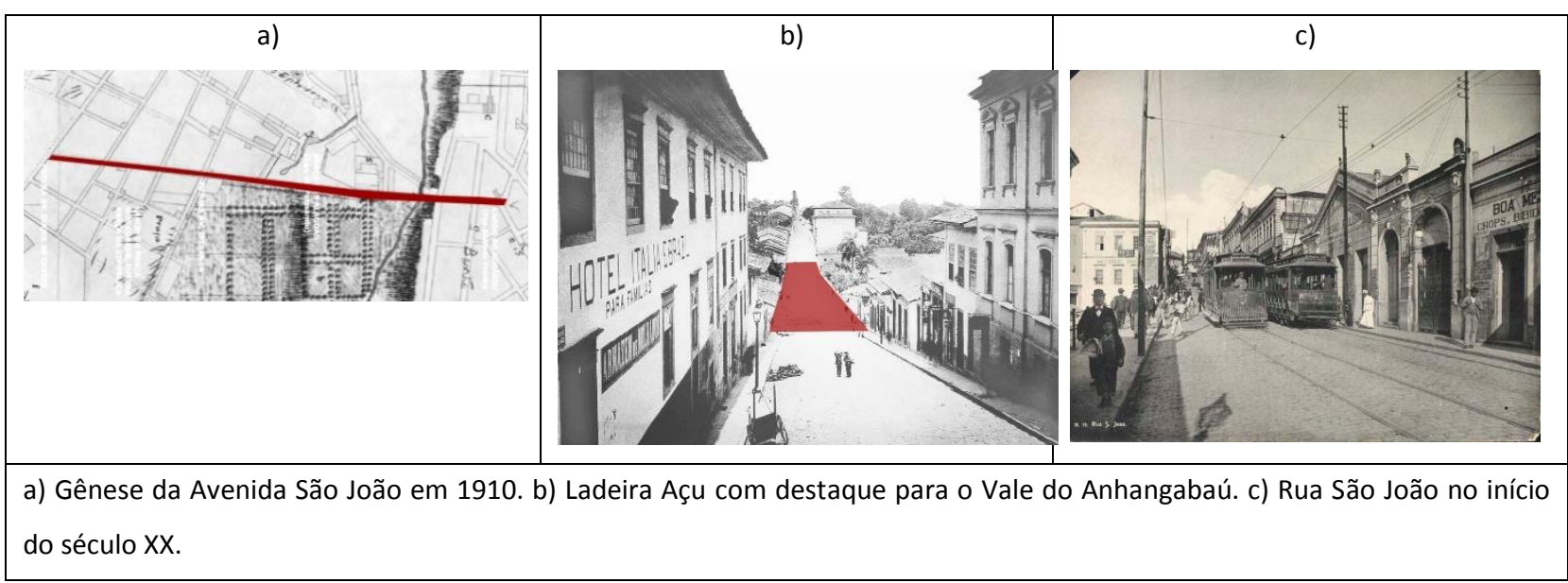

Fonte: a) RIOS, 2010, b) OLIVEIRA, 2014, c) GAENSLY, 2013. Organização: autor.

\subsection{Paisagem cultural atual da Avenida São João}

Após 1911, a paisagem cultural original da São João começou a ser modificada iniciando com o alargamento da rua:

Entre 1910 e 1937, sucessivas reformas, alargamentos e prolongamentos foram realizados. Numa de suas últimas reformas, entre as décadas de 80 e 90, a construção do novo "Vale do Anhangabaú" alterou o seu início, dando origem ao "Boulevard São João". Nome oficializado pelo Ato № 972, de 24 de agosto de 1916 (SÃO PAULO, S/D).

"A partir de 1911, a rua começara a ser alargada, e em 1940 já como "avenida", tomava as dimensões que tem atualmente. (...) em 1970, a última grande modificação: a construção do Elevado Costa e Silva, o popular 'Minhocão' sobre suas quadras finais" (RIOS, 2010).

Também, a paisagem da Avenida São João foi alterada a partir da verticalização das edificações iniciadas com o Ato Municipal no 663 de 1934 que possibilitou a construção de edifícios para habitação com tetos entre 50 e 80 metros nas avenidas mais largas. Em 1938 o Ato 1.366 estabeleceu novos gabaritos de altura de até 6 pavimentos na região do centro novo e em 1941, o Decreto Lei no 92 estabeleceu nova altura mínima obrigatória para 10 pavimentos e o térreo.

Localizada em uma área central, próxima ao Teatro Municipal, a região ficou conhecida pela grande oferta cultural, logo, cinemas de rua foram se instalando em seu entorno. Entre as edificações culturais podemos destacar: os hotéis Britania (1914) e Central (1918), o edifício Martinelli (1929), edifício Cineasta (1920) e edifício Correio (início da construção em 1919).

A partir da década de 1950, a paisagem da Avenida se encontrava bem alterada, devido verticalização, a quantidade de equipamentos culturais no entorno e instalação de hotéis para atender essa demanda de visitantes (Figura 3). 


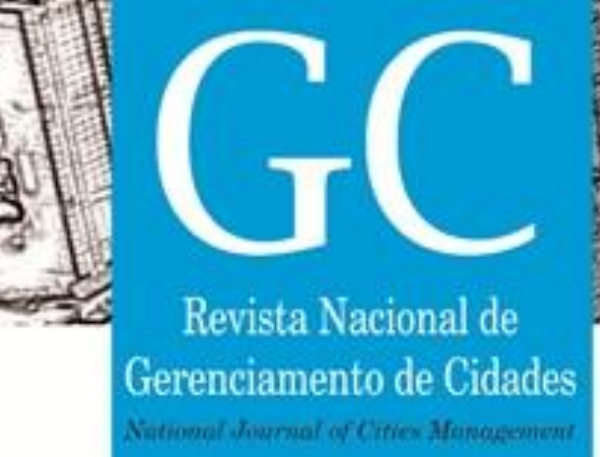

ISSN 2318-8472

v. $06, \mathrm{n} .38,2018$

Figura 3 - Avenida em 1950, com novos equipamentos culturais.

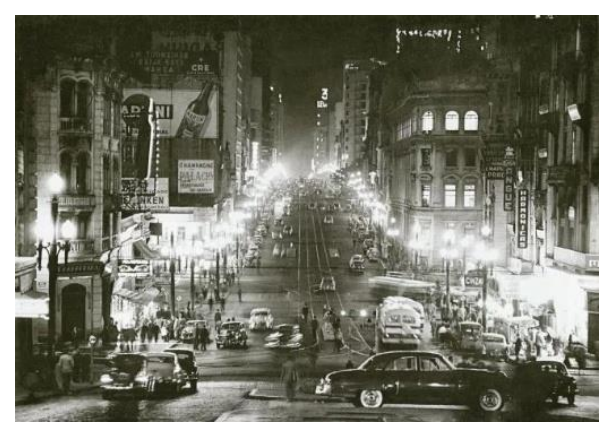

Fonte: SÃO PAULO, Acervo, 2017

A Figura 4 mostra a Avenida São João como se encontra hoje, e traz as camadas estratificadas dos cronotopos divididos em seis 'megablocos': Vale do Anhangabaú; Praças; Edifícios que remanesceram de 1910 a 1939; Edifícios que remanesceram de 1940 a 1969; Edifícios que remanesceram de 1970 a 1989; e Edifícios construídos a partir da década de 1990 até os dias atuais.

Como é possível analisar pela Figura 4, a paisagem cultural da Avenida São João alterou-se bastante nas últimas décadas, porém, alguns edifícios foram mantidos conservados em sua integridade.

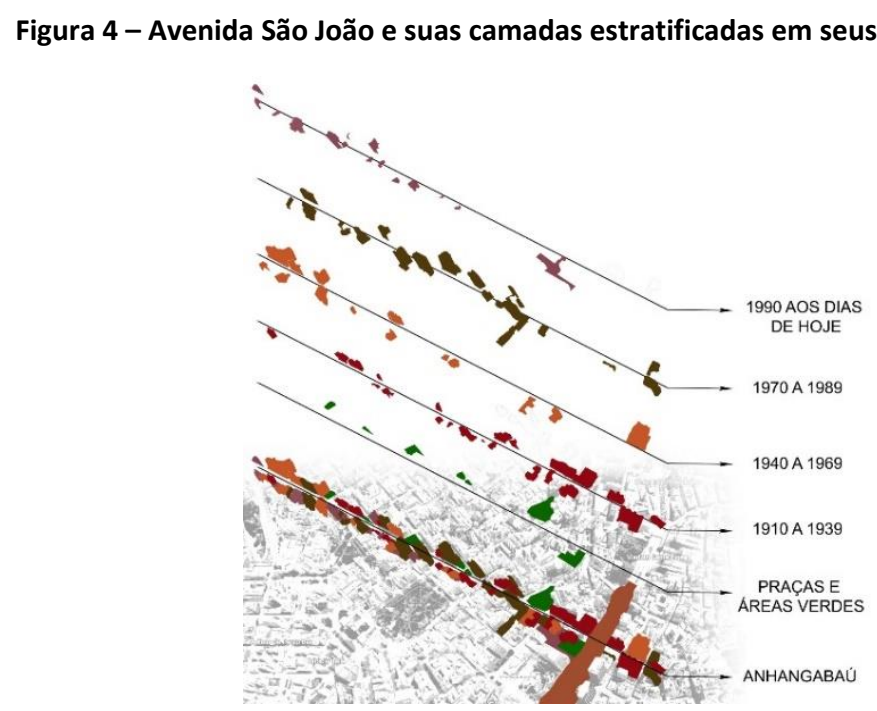

Fonte: 2017, pesquisa e edição do autor.

Os atuais elementos da paisagem cultural foram construídos nas décadas de 40,50 e 60, e mantidas ou preservadas a partir dos tombamentos realizados pelo CONDEPHAAT e COMPRESP, em 1968 e 1988, respectivamente (Figuras 5a e 5b).

Os edifícios mantidos na Avenida e tombados pelo CONPRESP estão presentes na Resolução n. 11/91 na Avenida São João são divididos nessa Resolução de acordo com as quadras em que estão localizadas e pelo número dos lotes em que se encontram: no Setor 1/Quadra 55 foram tombadas 6 


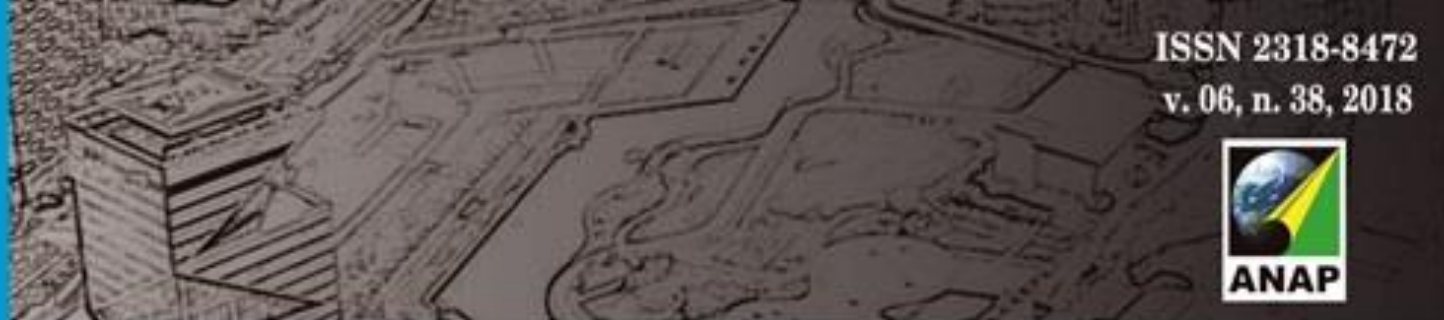

Gerenciamento de Cidades

edificações, no Setor 1/Quadra 56 foi tombada a Igreja de Nossa Senhora do Rosário dos Homens Pretos; no Setor 1/Quadra 58 foram 4 edificações, no Setor 1/Quadra 61 foram 5 edificações, no setor 1/Quadra 62 foi uma edificação, no Setor 1/Quadra 72 foi uma edificação, no Setor 6/Quadra 1 ㅇtambém uma edificação, no Setor 6/Quadra 17 foram 4 edificações, no Setor 6/Quadra 27 foram 4 edificações e no Setor 7/Quadra 75 foi uma edificação.

Deste tombamento, é possível traçar um panorama geral mostrando os edifícios relevantes nesta paisagem, como mostra a Figura $5 c$.

Figura 5 - Atual Avenida São João e edifícios tombados pelo COMPRESP

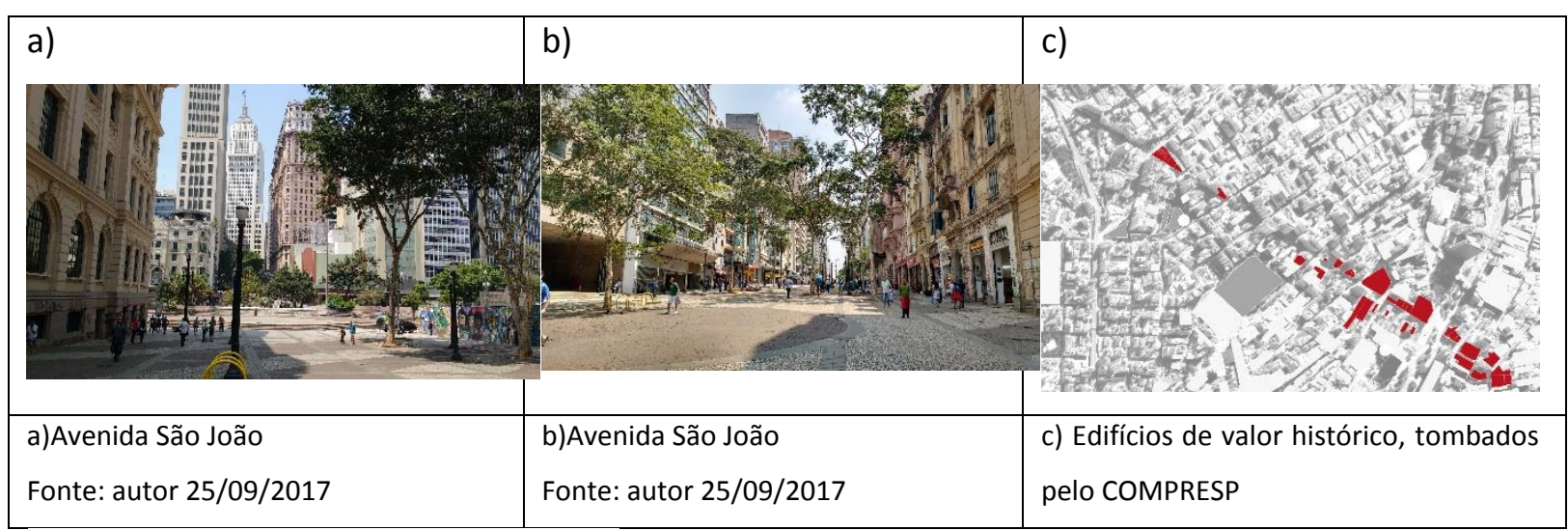

Fonte: COMPRESP, 1991, organizado pelo autor.

Dentre os edifícios tombados pelo CONDEPHAAT e COMPRESP destacamos: o Conservatório Dramático e Musical, edifício Martinelli, os hotéis Britânia e Central, edifício do Correio, edifício Cineasta e a Igreja Nossa Senhora do Rosário dos Homens Pretos.

O Conservatório Dramático e Musical foi construído em 1886, projeto do arquiteto alemão Guilherme Von Eÿe. Em 1899 o edifício passou por reformas, ganhou um anexo e se transformou num hotel de luxo, chamado Hotel Joachim's, vendido em 1901, e renomeado Hotel Panorama, por ser o mais alto e apresentar a melhor vista da cidade. Em 1909 passou a sediar o Conservatório Dramático e Musical (Figura 6a).

O edifício Martinelli de 20 andares foi projetado pelo italiano Giuseppe Martinelli, em 1924, a construção foi iniciada em 1924 e sua inauguração aconteceu em 1929, foram acrescentados novos pavimentos. Atualmente, é um dos principais símbolos do Brasil (PREFEITURA DE SÃO PAULO) (Figura 6b).

Os antigos hotéis Britânia e Central, na avenida São João, foram projetados por Ramos de Azevedo em 1914 e 1918 (Figura 6c)

A construção do edifício do Correio de São Paulo iniciou em 1919 e a inauguração ocorreu três anos depois. Restaurada, é um dos ícones da paisagem cultural, e fez com que a Praça Pedro Lessa ficasse mais conhecida como "Praça do Correio" (Figura 6d). 
Figura 6 - Edifícios da Avenida São João tombados pelo COMPRESP e CONDEPHAAT

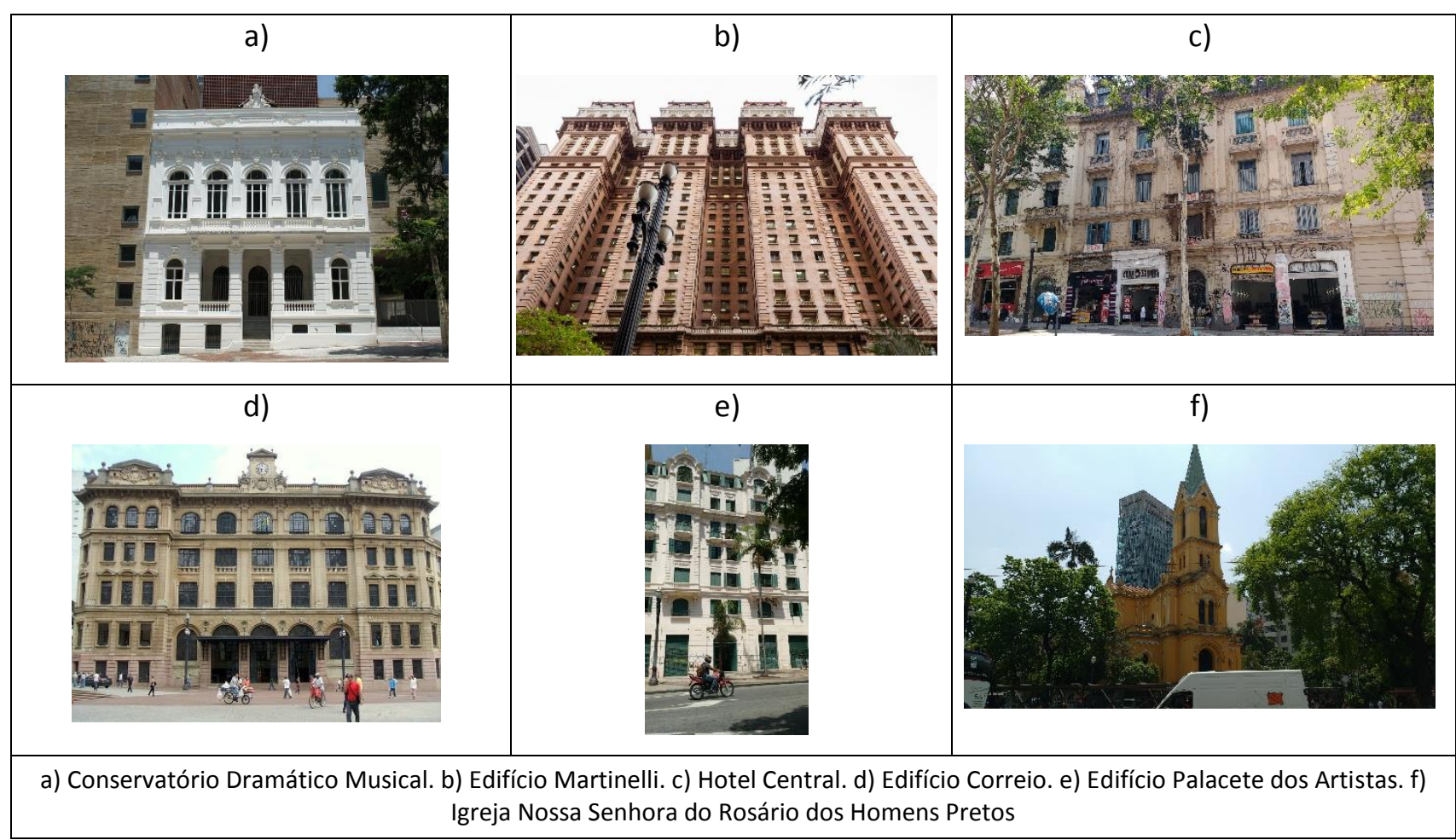

Fonte: a) SÃO PAULO, 2017 b) SÃO PAULO, 2017 c) autor 25/09/2017 d) SÃO PAULO 2017 e) autor 25/09/2017 f) autor 25/09/2017.

Cabe ressaltar que os tombamentos realizados pelo CONPRESP e pelo CONDEPHAAT levaram a preservação da paisagem cultural da Av. São João, sendo muito dos edifícios que compunham a paisagem cultural da avenida ao longo dos anos foram mantidas devido a isso.

\section{CONCLUSÃO}

A Avenida São João possui uma história pungente que se confunde com a própria história da Cidade de São Paulo. Vide que apenas 97 anos marcam essa separação entre descobrimento e fundação da cidade.

A gênese da paisagem cultural da rua São João se manteve até 1910, após esta data começa a transformação da paisagem cultural iniciando em 1910 com o alargamento da antiga Rua São João para configurar a avenida São João. Também, a verticalização começa com o Ato Municipal no 663 de 1934 que possibilita a construção de edifícios para habitação com tetos entre 50 e 80 metros nas avenidas mais largas, em 1938 se estabelece um novo gabarito de altura de até 6 pavimentos e em 1941 a altura mínima obrigatória passa para 10 pavimentos e o térreo. 


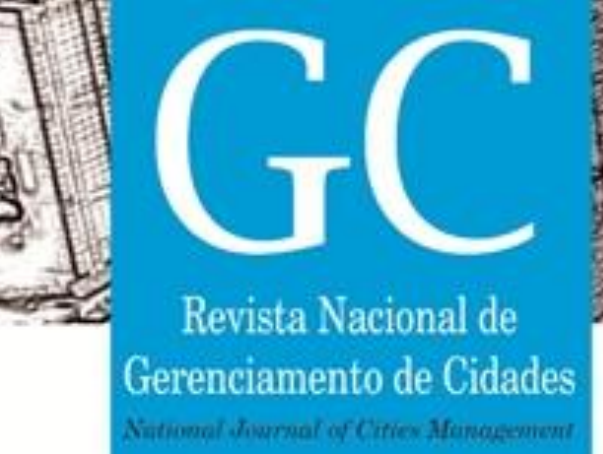

ISSN $2318-8472$

Os atuais elementos fixos da paisagem foram construídos nas décadas de 40, 50 e 60, e foram mantidas e preservadas a partir dos tombamentos realizados pelo CONDEPHAAT e pelo COMPRESP, em 1968 e 1988, respectivamente. Os elementos semifixos, como luminárias, lixeiras, bancos e sinalizações foram ampliados devido ao alto trafego, o que leva a alteração consequentemente dos elementos não fixos, como pessoas e automóveis que tem uma frequência maior, devido principalmente a instalação de novos equipamentos culturais na região como a Praça das Artes.

Os tombamentos realizados pelo CONDEPHAAT e COMPRESP frearam a crescente verticalização da avenida São João, preservaram as edificações relevantes para a história, a arquitetura, a cultura. Portanto, o trabalho ressalta que o tombamento é um instrumento legal de preservação dos elementos da paisagem cultural consequentemente da história, da memória e da indenidade.

\section{AGRADECIMENTO}

Agradeço a CAPES - Coordenação de Aperfeiçoamento de Pessoal de Nível Superior pelo apoio à pesquisa por meio da bolsa concedida.

\section{REFERÊNCIAS BIBLIOGRÁFICAS}

ABREU, Mauricio de Almeida. Sobre a memória das cidades. In: Revista da Faculdade de Letras - Geografia I série, Vol. XIV. Porto, p. 77-97.

BAKHTIN, Mikhail. Forms of time and of the chronotope in the novel. In: BAKHTIN, M. The dialogic imagination: four essays. Trad. Caryl Emerson, Michael Holquist. Austin: University of Texas Press, [1975] 1988, p. 84-258.

CARLI, Sandra Maria Marcondes Perito. Proposta de Projeto Inclusivo para o Programa Renova Centro - COHAB SP. Instituto Brasil Acessivel, 2012.

COMPRESP - Conselho Municipal de Preservação do Patrimônio Histórico, Cultural e Ambiental da Cidade de São Paulo. Resolução n. 11/91 - Aditamento à resolução n. 06/91.

MARICATO, H. Brasil cidades. Alternativas para a crise urbana. Petrópolis, RJ: Vozes, 2001.

MUNTAÑOLA, Josep Thornberg. El diálogo entre proyecto y lugar: Un reto para la arquitectura del siglo XXI. Barcelona, EI Lugar, 2006.

NOBRE, Eduardo Alberto Cusce. Políticas urbanas para o centro de São Paulo: renovação ou reabilitação? Pós V. 16, n. 25. São Paulo, jun. 2009.

OLIVEIRA, Abrahão, A História de uma das mais famosas Avenidas de São Paulo: Da Ladeira do Acú a Avenida São João. São Paulo in Foco, 8 abr. 2014. Disponível em: <http://www.saopauloinfoco.com.br/avenida-sao-joao/>. Acesso em: 29 jun. 2017.

PAULICEIA, Pauliceia Arquitetura, Restauro e Projetos Culturais Ltds. Projeto de Restauro - Edifício Cineasta, COHAB-SP, São Paulo, 2011.

RAPOPORT, Amos. Culture, Architecture and Design. Locke Science Publishing Co., Inc. 2005 


\section{Revista Nacional de}

RICOEUR, Paul. Arquitectura y narratividad. Revista Arquitectonics. Mind, Land \& Society. Arquitectura y Hermenéutica, Barcelona: UPC, n. 4, p. 9-29, 2003.

RIOS, Gilberto Calixto, São Paulo: Minha Cidade - Avenida São João, 2010, Levantamento fotográfico comentado. Disponível em: <http://imagensdesaopaulo.hd1.com.br> Acesso em: 30 jun. 2017.

RUSKIN, John. Las Siete Lámparas de la Arquitectura. Espanha, Valencia: F. Sempere, 1910.

SALCEDO, Rosío Fernández Baca. A reabilitação da residência nos centros históricos da América Latina: Cusco (Peru) e Ouro Preto (Brasil). São Paulo: Editora UNESP, 2007.

SÃO PAULO, Arquivo Histórico de São Paulo, S/D. Disponível em:

<http://www.dicionarioderuas.prefeitura.sp.gov.br/PaginasPublicas/ListaLogradouro.aspx>. Acesso em: 28 jun. 2017.

Arquivo Histórico de São Paulo, S/D. Disponível em: <http://spcultura.prefeitura.sp.gov.br/espaco/1874/>. Acesso em: 10 out. 2017.

VARGAS, Heliana C.; CASTILHO, Ana Luisa H. Intervenções em Centros Urbanos: Objetivos, Estratégias e Resultados. São Paulo: Manole. 2006. 